\title{
Introduction of case-based learning to teach Pharmacology to second year MBBS students
}

\author{
Megha Sood $^{1 *}$, Kulbir Kaur ${ }^{2}$, Rajiv Arora ${ }^{3}$
}

\author{
${ }^{1}$ Department of Pharmacology, ${ }^{2}$ Punjab Institute of Medical Sciences, Punjab, India \\ ${ }^{3}$ Department of Physiology, Punjab Institute of Medical Sciences, Punjab, India
}

Received: 02 December 2020

Accepted: 05 January 2021

\author{
*Correspondence: \\ Dr. Megha Sood, \\ Email:msood11@gmail.com
}

Copyright: ( $\odot$ the author(s), publisher and licensee Medip Academy. This is an open-access article distributed under the terms of the Creative Commons Attribution Non-Commercial License, which permits unrestricted non-commercial use, distribution, and reproduction in any medium, provided the original work is properly cited.

\begin{abstract}
Background: Our medical education system has various limitations. In the initial few years of medical education, the focus is more on teaching the theoretical aspect of various subjects and not to apply the knowledge gained to practice. It is important to stimulate a student's analytic thinking and provide them with an opportunity to see theory in practice. In case-based learning (CBL) a case acts as a stimulant of learning. The aim of the study was to introduce CBL in Pharmacology to teach second year MBBS students and see its effect on their performance. The study also aimed to get student and faculty (Department of Pharmacology) feedback on this teaching model.

Methods: A total 180 students of second prof. MBBS and faculty of Department of Pharmacology were included in the study. A total of two topics were taken for CBL sessions. The theory lecture of the first topic was conducted. The students were divided into smaller groups of 15 each and a pretest was taken. This was followed by CBL session and after that post-test was administered. The second topic was covered on similar format. At the end of the two sessions the student and faculty feedback were taken on a five-point Likert scale.

Results: A total 127 students participated in the study. 90\% of the students agreed or strongly agreed that CBL had been useful in understanding the topics and it will be useful for foundation of their clinical years. All faculty members agreed that CBL does improve student teacher interaction but they found CBL to be time consuming.

Conclusions: CBL was well accepted by the students and they want that other topics should be taken up by this method. The faculty also believes that it is worth giving a try but at the same time CBL is time consuming and it may be possible to conduct it for only a few topics in a session.
\end{abstract}

Keywords: Case based learning, Medical education, Pharmacology

\section{INTRODUCTION}

The focus of our medical education system in the initial few years of medical education is more on teaching the theoretical aspect of various subjects. Since the students are not applying the knowledge gained to practice, this results in lack of interest as well as critical thinking which gradually translates into student's inability of 'problem solving'. In case based learning (CBL), a case acts as a stimulant of learning. It is written as a problem that provides a clinical situation along with information on clinical signs, symptoms and laboratory investigations. ${ }^{1}$
Case based learning is a form of small group learning which incorporates group discussion of case scenarios, active participation of all members and learning together in a group. In these groups' students work together and try to solve the clinical problem using critical thinking. Both the faculty and students prepare in advance and the case is discussed under guidance. ${ }^{2}$ The teacher facilitates the discussion and corrects the mistakes of the students. ${ }^{3,4}$ Discovery is encouraged in a format in which both students and teachers share responsibility for learning important points. That is why CBL has also been termed as a guided inquiry approach. ${ }^{5}$ The main goal of case-based learning is 
to prepare students for future clinical practice. It integrates basic and clinical sciences and, in the process, provides clinical relevance to basic science teaching. ${ }^{6,7}$

The aim of the study was to introduce CBL in Pharmacology to teach second year MBBS students and see its effect on their performance. The study also aimed to get student and faculty (Department of Pharmacology) feedback on this teaching model.

Specific objectives- The specific objectives of the study were to build up knowledge of pharmacology and to stimulate higher cognition by critical thinking

\section{METHODS}

The study was started after clearance from institutional Ethics Committee. 180 students of second prof. MBBS and faculty of Department of Pharmacology were included in the study. The faculty questionnaire used in the study was validated by the MEU members. The student questionnaire was validated by 10 students of $5^{\text {th }}$ semester who were not part of this study. The students and faculty members were sensitized to case-based learning. Two sessions of CBL were planned. The two topics which were covered in CBL were rheumatoid arthritis and gout. Each topic was dealt separately. The theory lecture of the first topic (rheumatoid arthritis) was taken. The students were divided into two batches of 90 students each and each batch of 90 students was further divided into 6 batches of 15 students each. The second group of 90 students was taken after the session with first 90 was over. Before starting the session, a pretest on rheumatoid arthritis was administered to the students. This was followed by the CBL session. During the CBL session the students were distributed handouts which had details of case history, physical examination and laboratory examination. The students took turns to read out the handout. The students discussed the major problems in the case and tried to solve them. The focus of CBL was on problem solving, to model what will occur in the future when students encounter real clinical problems. The teachers guided the flow of the discussion. At the end of the CBL session a post test was administered. The second topic of Gout was covered in similar format. At the end of the second session the students were administered a feedback form which consisted of ten statements to which the students had to respond on a five-point Likert scale. After this the faculty was administered a feedback questionnaire to which they had to respond on a five-point Likert scale in order to know their views on CBL. The data collected was analyzed and expressed in percentages. The data was tabulated and expressed on graphs as well.

\section{RESULTS}

\section{Data analysis second year MBBS students}

We have 180 students in our MBBS second prof. out of which 127 students participated in the study. The students who were absent in one or the other session were excluded from the final analysis.

Table 1: Response to student feedback questionnaire.

\begin{tabular}{|llllll|}
\hline Variables & $\begin{array}{l}\text { Strongly } \\
\text { disagree }(\%)\end{array}$ & $\begin{array}{l}\text { Disagree } \\
(\%)\end{array}$ & $\begin{array}{l}\text { Uncertain } \\
(\%)\end{array}$ & $\begin{array}{l}\text { Agree } \\
(\%)\end{array}$ & $\begin{array}{l}\text { Strongly } \\
\text { agree }(\%)\end{array}$ \\
\hline $\begin{array}{l}\text { CBL has been useful in } \\
\text { understanding the topic }\end{array}$ & $3(2.4)$ & $2(1.6)$ & $8(6.3)$ & $64(50.4)$ & $50(39.4)$ \\
\hline $\begin{array}{l}\text { CBL has helped in better } \\
\text { understanding of basic concepts } \\
\text { and its relevance }\end{array}$ & $4(3.1)$ & $2(1.6)$ & $8(6.3)$ & $73(57.5)$ & $40(31.5)$ \\
$\begin{array}{l}\text { CBL is a useful foundation for } \\
\text { my clinical years }\end{array}$ & & $3(2.4)$ & $10(7.9)$ & $65(51.2)$ & $49(38.6)$ \\
\hline $\begin{array}{l}\text { CBL has contributed to interest } \\
\text { in the subject }\end{array}$ & $2(1.6)$ & $3(2.4)$ & $8(6.3)$ & $66(52)$ & $48(37.8)$ \\
\hline $\begin{array}{l}\text { CBL is a useful for preparation } \\
\text { of clinical problem solving }\end{array}$ & & $1(0.8)$ & $8(6.3)$ & $53(41.7)$ & $65(51.2)$ \\
\hline $\begin{array}{l}\text { The discussion sessions during } \\
\text { CBL facilitated interaction } \\
\text { between faculty and students }\end{array}$ & $4(3.1)$ & $1(0.8)$ & $8(6.3)$ & $59(46.5)$ & $55(43.3)$ \\
\hline $\begin{array}{l}\text { CBL should be used along with } \\
\text { didactic lectures }\end{array}$ & $4(3.1)$ & $2(1.6)$ & $17(13.4)$ & $59(46.5)$ & $45(35.4)$ \\
\hline $\begin{array}{l}\text { Other topics should be taught by } \\
\text { this method }\end{array}$ & $2(1.6)$ & $2(1.6)$ & $14(11)$ & $70(55.1)$ & $39(30.7)$ \\
\hline $\begin{array}{l}\text { CBL may contribute to better } \\
\text { academic performance }\end{array}$ & & $2(1.6)$ & $13(10.2)$ & $70(55.1)$ & $42(33.1)$ \\
\hline I enjoyed case-based learning & $3(2.4)$ & $1(0.8)$ & $8(6.3)$ & $68(53.5)$ & $47(37)$ \\
\hline
\end{tabular}




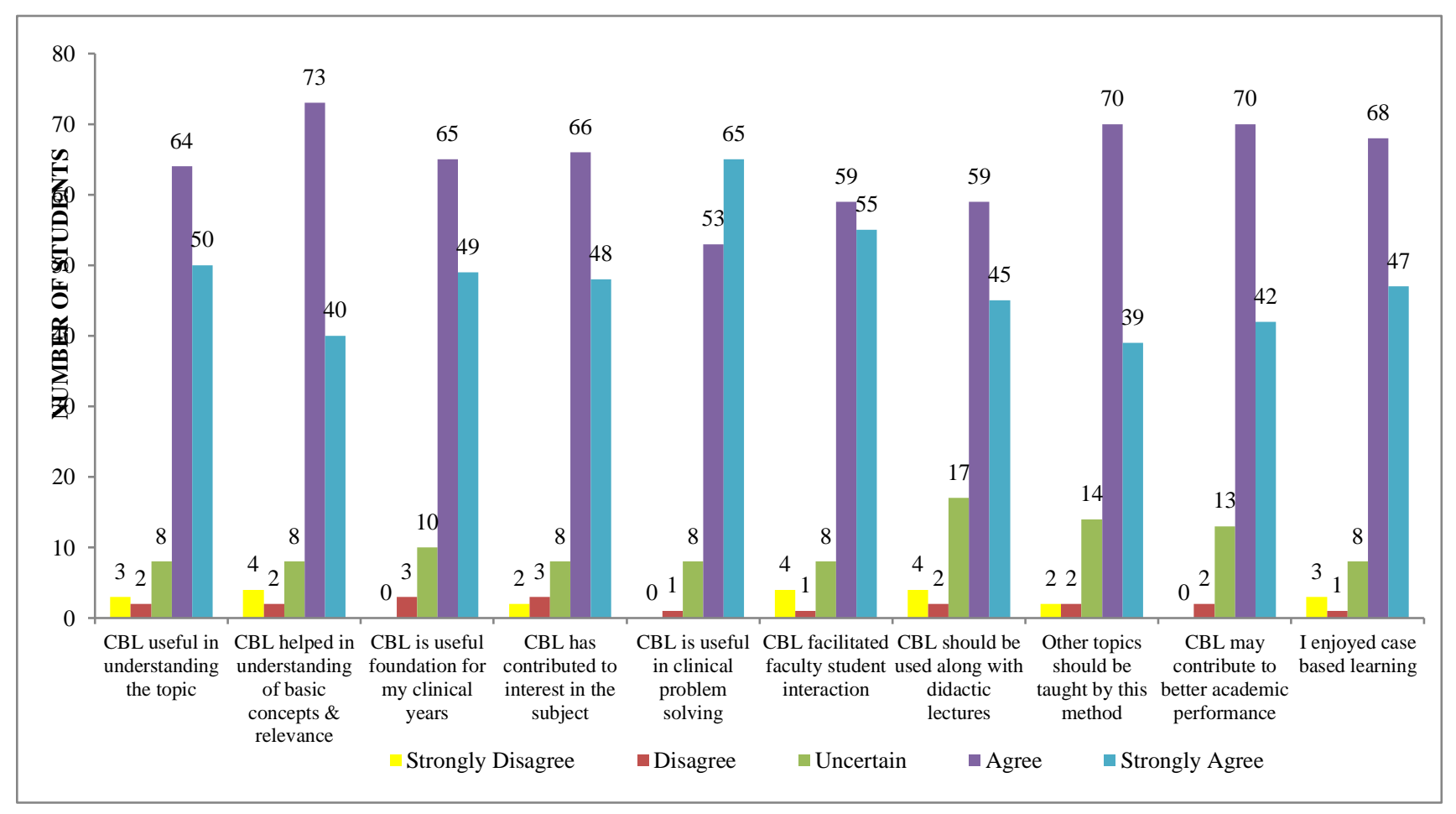

Figure 1: Analysis of student response.

On analyzing the first three statements of the questionnaire it was quite clear that 50 or more than $50 \%$ students agreed that CBL had been useful for understanding the topic, it had contributed to better understanding of concepts and this methodology will be useful for their clinical years. $52 \%$ of the students responded that CBL had contributed to the interest in the subject whereas $37.8 \%$ strongly agreed to the statement. $51.2 \%$ of the students strongly agreed that CBL will be useful in preparation of their future clinical problem solving. $46.5 \%$ agreed and $43.3 \%$ strongly agreed that the sessions had facilitated interaction between faculty and students. $55.1 \%$ of students agreed that CBL may contribute to better academic performance and other topics should be taught by these methods. $46.5 \%$ agreed and $35.4 \%$ strongly agreed that CBL should be used along with didactic lectures. 53.5\% agreed and $37 \%$ strongly agreed that they enjoyed case-based learning.

\section{Data analysis of student's pre-test and post-test performance}

The average score of students on the pre-test for rheumatoid arthritis was 5.6 and that for the post test was 6 . The average score for pre-test for gout was 5 and for the post test was 5.5. So, there was only slight improvement in the post test scores.

\section{Data analysis of faculty feedback}

There are 6 post graduate faculty members in the department of pharmacology at our institute. The average teaching experience of the faculty member is 10 years. The attitudes and opinions of the faculty members were taken by asking them the extent to which they agree or disagree with the set of statements. The response was gauged using a five level Likert scale.

Three out of the six faculty members that is $50 \%$ of the faculty members were of the opinion that CBL facilitates teaching and learning in Pharmacology while 2 members disagreed to this.

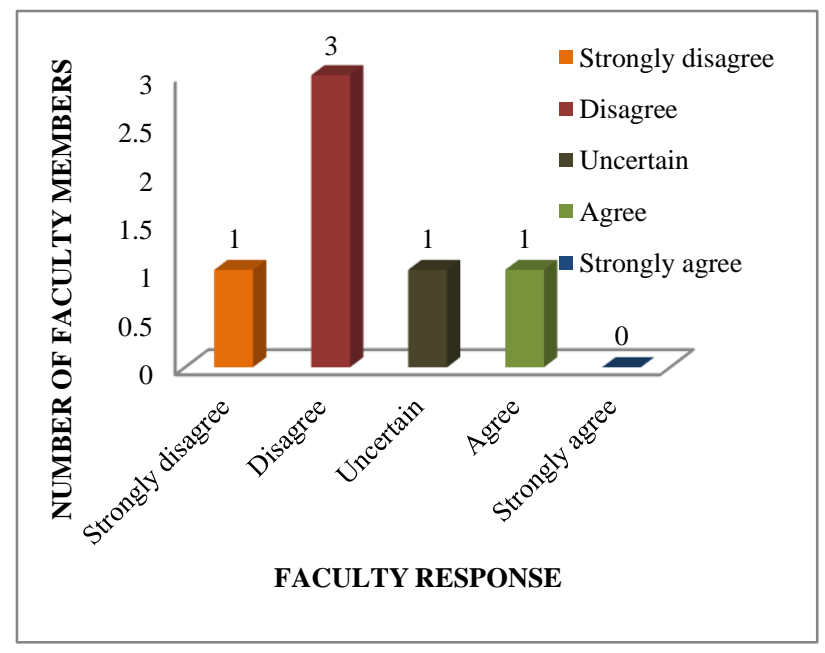

Figure 2: Faculty response: CBL reduces teaching time.

Majority of the faculty members were of the opinion that CBL is time consuming and does not reduce teaching time for a particular topic. Four out of the six faculty members 
disagreed or strongly disagreed to the statement that CBL reduced teaching time. This is in confluence that small group teaching methods which require teamwork and problem solving like case-based learning are faculty and resource intensive (Figure 2).

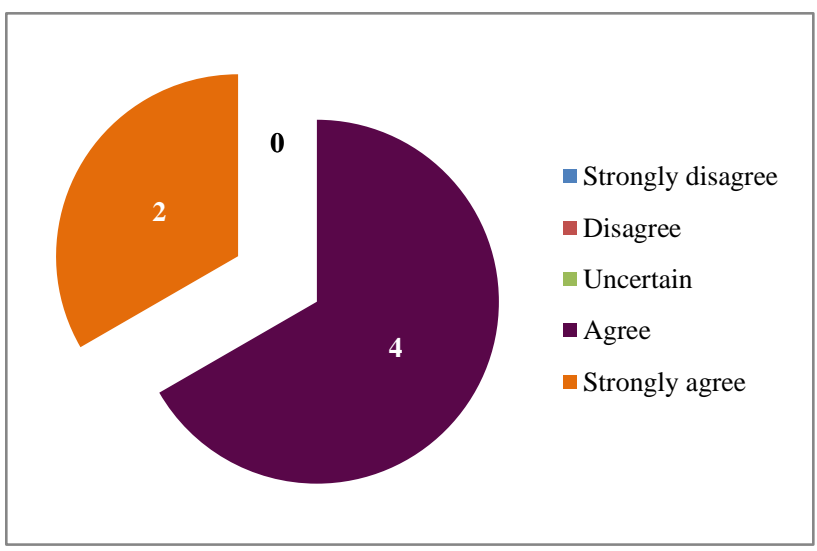

Figure 3: faculty response: CBL improved student teacher interaction.

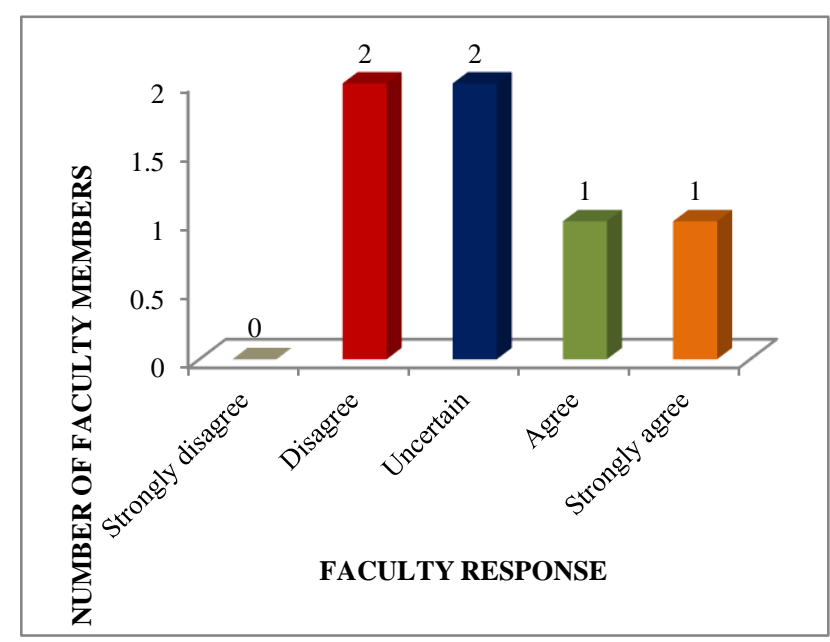

Figure 4: After CBL students discuss the topic more.

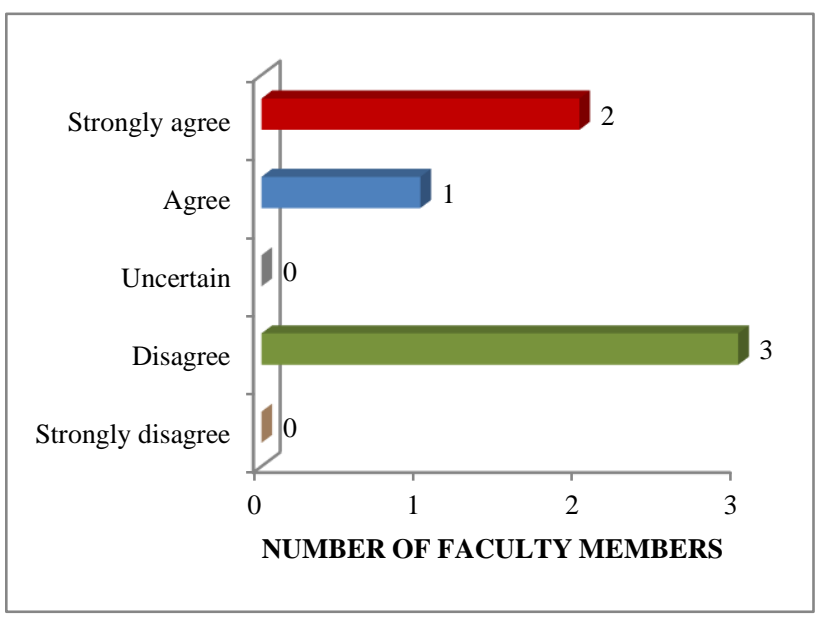

Figure 5: Students take more active part in learning.
All the faculty members agreed that CBL contributed to increased interaction between faculty and students. Four members agreed and two members strongly agreed to the statement (Figure 3).

The opinion of the faculty was divided on the statement that CBL led to deeper understanding of concepts and critical thinking skills. The response of the faculty varied from strongly disagreeing to strongly agreeing to the statement.

The opinion of the faculty was equally divided on the effect of CBL on topic discussion and student's active participation in learning (Figure 4 and 5).

Two of the faculty members felt that CBL is not useless for our traditional examination pattern and discussing topic by this method will also help students score in descriptive questions which are a part of our university exams. Most of the faculty members think that CBL is worth trying ( 2 members strongly agreed and 1 member agreed to the statement). Two of the faculty members disagreed to the statement and did not find it necessary for trying this teaching learning method in present scenario.

\section{DISCUSSION}

Case based learning is a teaching learning methodology which involves student exposure to cases in order to prepare them for future clinical practice. In CBL the learning is in context of a case. CBL aims to link theory and practice which is important for future professional practice. The approach tries to move the focus of students from just acquiring and reproducing knowledge but its application as well. In our health care system, it is important that the learning activities be based on cases. Using case-based approach enhances the relevance of basic sciences by focusing on real life case scenarios. Case based learning is a learner centered approach and allows students to discuss clinical situations. In our study 127 students of second prof. participated. The response of students to CBL has been quite positive. Majority of the students agreed or strongly agreed that CBL had been useful in understanding the topics and had helped them better understand the basic concepts. CBL also facilitated the development of knowledge that is relevant to clinical practice and helped them realize why these topics were being taught. Other studies on case-based learning have shown similar results as our study. A study of student feedback on CBL had shown that CBL helped the students to understand the fundamental and theoretical concepts and forced them to think as professionals. ${ }^{7} \mathrm{CBL}$ also improved student participation and student satisfaction. However, a study by Curran et al 2008 found that student satisfaction with CBL seems to be related more to the group learning process rather than the CBL itself. According to them students became more positive towards aspects of the group activity and towards group work. ${ }^{8}$ In our study majority of the students agreed or strongly agreed that CBL will be useful for foundation of their 
clinical years, it contributed to the interest in the subject and helped in better interaction between students and faculty. Studies have shown that case-based approach engages students in discussion of specific situations and thus can be perceived challenging, interesting and helpful towards learning. ${ }^{9}$ It promotes team work, retention of key concepts and their application to patient care situations. Our study showed that majority $(93 \%)$ students feel that CBL will be useful in clinical problem solving and it should be used along with didactic lectures.

Studies on CBL have also gauged other aspects such as perception of students as far as confidence is concerned and improvement in communication skills. ${ }^{11}$ In these studies students felt that CBL improved confidence and cases provided had a good link with real life practice.

In our study CBL was perceived positively by most of the students. But there are few studies where students were not sure if $\mathrm{CBL}$ helped them prepare for their summative assessments. In our study also, a few students were not convinced that CBL will help improve their academic performance. A few studies have shown that these activities increase work load and a lot of time was required for CBL. ${ }^{6}$

We have not compared CBL with conventional tutorials but a study carried out by Hashim et al evaluated the perception of $4^{\text {th }}$ year undergraduate medical students regarding case-based learning method and tutorial format, it was deduced that the case-based learning format was significantly more appreciated and favored as a learning strategy by students. ${ }^{12}$

Analyses of the faculty response in our study showed that they found that CBL facilitated teaching and learning in Pharmacology, improved student teacher interaction and discussing topic by this method will help students score in descriptive questions which are a part of our university exams. The faculty members felt that there were certain active participants (students) in the group who tend to dominate the case discussion. They felt that CBL is worth trying but one should take into consideration the time constraint. Another limitation is that since it's a small group discussion before conducting CBL full faculty presence needs to be ensured.

As previous studies conducted on CBL, our study also shows that CBL is well accepted by the students. But at the same time, we should keep in mind that small group discussions like CBL are resource intensive, require full faculty participation and are time consuming. ${ }^{13}$ The faculty members need to put in lot of effort for designing case studies and discussing them in detail. So presently CBL can be limited to few difficult topics.

\section{Limitations}

Due to time constraint only two sessions of CBL could be conducted. That may be one of the reasons we could not see any significant difference in the academic performance of the participating students. Data of some of the students had to be excluded as they were absent in the classes of these topics or subsequent CBL sessions. Greater participation would have helped in getting better results. Long term outcomes such as actual improvement in communication skills, students' problem-solving ability and practice behavior can only be studied only by following up the students to their clinical practice years. All these cannot be deduced by this study.

\section{CONCLUSION}

CBL was well accepted by the students and they want that other topics should be taken up by this method. The faculty also believes that it is worth giving a try as it facilitates teaching and learning in Pharmacology and contributes to improved faculty-student interaction. But at the same time faculty believes that CBL is time consuming and it may be possible to conduct it for only a few topics in a session.

\section{ACKNOWLEDGEMENTS}

Authors would like to thank to all the faculty members of the Department of Pharmacology for their help and support in conducting the sessions on case-based learning.

\section{Funding: No funding sources}

Conflict of interest: None declared

Ethical approval: The study was approved by the Institutional Ethics Committee

\section{REFERENCES}

1. Williams B. Case based learning-a review of the literature: is there scope for this educational paradigm in prehospital education? Emerg Med J. 2005;22:57781.

2. McLean SF. Case based learning and its application in Medical and health care fields: A review of worldwide literature. J Med educ curricular develop. 2016:3:39-49.

3. Dubey S, Dubey AK. Promotion of higher order of cognition in undergraduate medical students using case-based approach. J Educ Health Promot. 2017;6:75.

4. Barrows HS. A taxomony of problem-based learning concepts. Med Educ. 1986;20:481-6.

5. Malathi S, Wilkes M, Stevenson F, Nguyen T, Slavin S. Comparing Problem-Based Learning with CaseBased Learning: Effects of a Major Curricular Shift at Two Institutions. Acad Med. 2007;82(1):74-82.

6. Thistlewaite JE, Davies D, Ekeocha S, Kidd JM, MacDougall C, Matthews P et al. The effectiveness of case-based learning in health professional education. A BEME systematic review. BEME guide number 23. Med Teach. 2012;34 E421-44.

7. Jesus A, Gomes MJ, Cruz A. A case-based learning model in therapeutics. Inov Pharm. 2012;3(4):91. 
8. Curran VR, Sharpe D, Forristall J, Flynn K. Student satisfaction and perceptions of small group process in case-based interprofessional learning. Med Teach. 2008;30(4):431-3.

9. Joseph A. Mayo Using case-based instruction to bridge the gap between theory and practice in psychology of adjustment. J Constructivist Psychol. 2010;17(2):137-46.

10. Malau-Aduli BS, Lee YSA, Cooling N, Catchpole M, Jose M, Turner R. Retention of knowledge and perceived relevance of basic sciences in an integrated case-based learning (CBL) curriculum. BMC Med Educ. 2013;13:139.

11. Yoo MS, Park HR. Effects of case-based learning on communication skills, problem solving ability and learning motivation in nursing students. Nurs Health Sci. 2015;17(2):166-72.

12. Hashim R, Azam N, Shafi M, Majeed S, Ali S. Perceptions of undergraduate medical students regarding case based learning and tutorial format. J Pak Med Assoc. 2015;65(10):1050-5.

13. Mrudula C, Rajneesh, Challa SR. Perception of students and faculty regarding the implementation of Case Based Learning in pre and para clinical MBBS students. Int J Curr Res Biol Med. 2017;2(5):6-11.

Cite this article as: Sood M, Kaur K, Arora R. Introduction of case-based learning to teach Pharmacology to second year MBBS students. Int $\mathbf{J}$ Basic Clin Pharmacol 2021;10:176-81. 